Canadian Journal of Fisheries and Aquatic Sciences, Vol. 52, No. 1, 1995, pp. 136-140 ISSN: 0706-652X

doi:10.1139/f95-013

http://article.pubs.nrccnrc.gc.ca/RPAS/RPViewDoc?_handler_=HandleInitialGet\&calyLang=eng\&journal=cjf as\&volume $=52 \&$ articleFile=f95-013.pdf

http://pubs.nrc-cnrc.gc.ca/eng/index.html (c) National Research Council of Canada All rights reserved. 


\title{
Density dependent survival as a function of size in juvenile salmonids in streams
}

\author{
Flizabeth A. Marschall and Larry B. Crowder
}

\begin{abstract}
The bioenergetic mechanism of density-dependent survival in juvenile stream salmonids was modeled using the relationship between density, food availability, and body size for a foodlimited stream system. With a consumption-rate function estimated from laboratory experiments reported in the literature, we developed a function to predict maximum density of stream-resident juvenile salmonids of different sizes. This function can thus predict effective density based on both numbers and sizes of fish. Density predictions from this mechanistic function did not differ from predictions in the literature based on an empirically derived function describing the relationship between minimum territory size and body size in age- 0 salmonids in streams, but it did suggest a bioenergetic mechanism for these relationships, linking size and consumption rate to the available food. Finally, we proposed a model of per capita survival rate as a function of the numbers and sizes in a cohort of stream-resident juvenile salmonids.
\end{abstract}

Résumé : Nous avons modélisé le mécanisme bioénergétique de la survie dépendante de la densité chez des salmonidés juvéniles d'eau courante en utilisant la relation entre la densité, la disponibilité de la nourriture et la taille corporelle pour un système lotique oligotrophe. À l'aide d'une fonction du taux de consommation estimé à partir d'expériences de laboratoire rapportées dans la littérature, nous avons élaboré une fonction permettant de prédire la densité maximale de salmonidés juvéniles d'eau courante de différentes tailles. Cette fonction peut donc prédire la densité effective à partir du nombre de poissons et de leur taille. Les prédictions de la densité à partir de cette fonction mécaniste ne différaient pas des prévisions trouvées dans la littérature et fondées sur une fonction empirique décrivant la relation entre la superficie minimum du territoire et la taille corporelle chez des salmonidés d'âge 0 en rivière, mais elles ont permis de décrire un mécanisme bioénergétique pour ces relations, en liant la taille et le taux de consommation à la nourriture disponible. Enfin, nous proposons un modèle du taux de survie par individu comme fonction du nombre de poissons et des tailles dans une cohorte de salmonidés juvéniles dulcicoles. [Traduit par la Rédaction]

Survival early in the life history of salmonids in streams has been shown to be dependent on cohort density (LeCren 1965; Chapman 1966; Allen 1969; Elliott 1987, 1989, 1990; Titus 1990). Predicting dynamics of a cohort under different environmental conditions requires understanding the basis of this density dependence. Individual salmonids defend territories in the streams beginning very early in their life history (Latta 1969; LeCren 1972; Noakes 1980; Titus 1990), so space is clearly an important resource. But space itself may be a surrogate for some vital resource available in that space. In salmonids, territories are pri-

Received July 6, 1993. Accepted June 15, 1994.

J11996

E.A. Marschall. Department of Zoology, 1735 Neil Avenue, The Ohio State University, Columbus, OH 43210, USA.

L.B. Crowder. ${ }^{1}$ Department of Zoology, North Carolina State University, Raleigh, NC 27965-7617, USA.

Present address: Duke University Marine Lab, 135 Duke Marine Lab Road, Beaufort, NC 28516-9721, USA. marily for feedings, so density of fish in a particular space during the growing season depends on food availability (Mason and Chapman 1965; Slaney and Northcote 1974; Mason 1976; Dill et al. 1981). Because individual consumption rate increases with body size (Elliott 1975), density of fish supported by a particular food resource also will depend on body sizes.

Here, we model the relationship between density of first-year stream salmonids, food availability, and body size. We include a brief description of an analogous function for space-limited stream salmonids, originally derived by Grant and Kramer (1990) with a new parameter estimate from Grant (1993). Finally, we give a function for density-dependent survival of young stream salmonids in a food-limited system.

\section{Model development}

Food limitation

When a food is limited, a given area of stream will be able to support fewer individuals in a cohort of large fish than in a cohort of small fish. The impact of a cohort of

Can J. Fish. Aquat. Sci. 52: 136-140 (1995). Printed in Canada / Imprimé au Canada 

small fish on prey resources will be less than the impact of an equal number of large fish. Assuming that food is limiting, the strength of density dependence will be based not only on the absolute number of fish, but on the effect that the number has on the food resources. We refer to this as the "effective density" or the consumption-potential density of the cohort. Note that when we refer to large fish and small fish, we are only referring to those sizes expressed throughout the first growing season.

Clearly, this effective density will be a function of both the body sizes and number of fish in a cohort. We assume here that a given amount of food will support a given effective density of fish, but that the actual numbers supported will depend on their body sizes. Because daily consumption rate is a function of body size, we can derive a functional link between number and size of fish in a cohort. Under constant environmental conditions, daily food consumptions, $C$ (g dry wt. $\mathrm{d}^{-1}$ ) as a function of body size has the form

$$
C(m)=\alpha m^{\beta}
$$

in most fish (Wooton 1990), where $m$ is mass ( $\mathrm{g}$ ) of an individual. Parameters $\alpha$ and $\beta$ (see Table 1 for definitions) have been estimated for brown trout (Salmo trutta, a stream salmonid) feeding ad libitum at $\alpha=0.04$ and $\beta=0.77$ (Elliott 1975). If a habitat has $F$ total available food density per day ( $\mathrm{g}$ dry wt. $\mathrm{m}^{-2} \cdot \mathrm{d}^{-1}$ ), and if a density of $n_{F}$ individuals per square metre with individual body mass $m$ are using $\rho_{F}$ proportion of this food, then

$$
\rho_{F} F=n_{F} \alpha m^{\beta} .
$$

So $n_{F} \alpha m^{\beta}$ represents the effective density, relative to food available, of this group of fish. Clearly, as body mass $m$ increases, numbers $n$ must decrease to maintain an equivalent impact on the food resources (i.e., an equivalent effective density):

$$
\text { [1] } n_{F}=\rho_{F} F \frac{1}{\alpha} m^{-\beta} \text {. }
$$

Note that $\alpha$ and $\beta$ have been estimated independently of this function for brown trout (Elliott 1975), but that $\rho_{F} F$ (total amount of available food used) often will be much more difficult to estimate.

\section{Space limitation}

Grant and Kramer (1990) empirically estimated an analogous function for space limitation in stream salmonids. In a review of the literature, they found 23 studies in which minimum territory size $\left(\mathrm{cm}^{2}\right)$ and fish sizes were both measured. They regressed $\log (1 /$ territory size) on $\log$ (fish size) to obtain space-limited density $\left(n_{S}\right)$ as a function of fish size:

$$
n_{S}=\rho_{s} \gamma \ell^{-\omega}
$$

where $\omega$ and $\gamma$ are both estimated by regression, $\rho_{S}$ is the proportion of total habitat used, and $\ell$ is fish total length $(\mathrm{cm})$. Their parameters were estimated by regression under the assumption that all of the available habitat was used, i.e., $\rho_{S}=1$ (because data used in the regression are minimum territory sizes when habitat is at saturation, Grant and

\begin{tabular}{|c|c|}
\hline Parameter & Definition \\
\hline$C$ & Individual daily food consumption $\left(\mathrm{g}\right.$ dry $w t \cdot \mathrm{d}^{-1}$ ) \\
\hline$m$ & Individual body mass $(\mathrm{g})$ \\
\hline FL & Fork length $(\mathrm{cm})$ \\
\hline$\ell$ & Total length $(\mathrm{cm})$ \\
\hline$F$ & $\begin{array}{l}\text { Total daily available food density } \\
\qquad\left(\mathrm{g} \text { dry } \mathrm{wt} \cdot \mathrm{m}^{-1} \cdot \mathrm{d}^{-1}\right)\end{array}$ \\
\hline$\rho_{F}$ & $\begin{array}{l}\text { Proportion of total food used in food limitation } \\
\text { model }\end{array}$ \\
\hline$\rho_{S}$ & $\begin{array}{l}\text { Proportion of total space used in space } \\
\text { limitation model }\end{array}$ \\
\hline$n_{F}$ & Density of age-0 fish in food limitation model \\
\hline$n_{S}$ & Density of age- 0 fish in space limitation model \\
\hline$\alpha$ & $\begin{array}{l}\text { Intercept of consumption versus mass } \\
\text { relationship (estimated from Elliott 1975) }\end{array}$ \\
\hline$\beta$ & $\begin{array}{l}\text { Exponent of consumption versus mass } \\
\text { relationship (estimated from Elliott 1975) }\end{array}$ \\
\hline$\gamma$ & $\begin{array}{l}\text { Intercept of density versus length relationship, } \\
\text { best-fit estimate }\end{array}$ \\
\hline$\omega$ & $\begin{array}{l}\text { Exponent of density versus length relationship, } \\
\text { best-fit estimate }\end{array}$ \\
\hline $\mathrm{D}$ & $\begin{array}{l}\text { Effective density, a sum of number of fish times } \\
\text { their potential consumption }\end{array}$ \\
\hline
\end{tabular}
Kramer 1990).
Table 1. Summary of definition of parameters used in the text.

\section{Model comparison}

To compare the food limitation model with the Grant and Kramer (1990) model, we described both as a functions of total length, rather than mass. We used the relationships

$$
m=85.11(F L)^{3.03}
$$

(Grant and Kramer 1990) and

$$
F L=0.9684 \ell
$$

(Carlander 1969) to give a relationship to convert between $\ell$ (total length in $\mathrm{cm}$ ) and $m$ (mass in $\mathrm{g}$ ):

$$
m=77.23 \ell^{3.03} \text {. }
$$

Then our original function describing $n_{F}$ as a function of $m$ (eq. 1) can be rewritten as function of $\ell$ (where $\alpha=$ $0.04, \beta=0.77$, Elliott 1975)

$$
n_{F}=\rho_{F} F \frac{1}{\alpha}\left(77.23 \ell^{3.03}\right)^{-\beta}=\rho_{F} F \cdot 0.8798 \ell^{-2.33} .
$$

We also assumed $\rho_{F}=1$, meaning the population is at the level of saturation of the food resource, to make it comparable to Grant and Kramer's estimate of $\omega$ and $\gamma$ assuming $\rho_{S}=1$.

Although we have estimates for $\alpha$ and $\beta$ (from Elliott 1975 ), we must estimate $F$ to be able to make comparisons between the two functions. We can estimate $F$ from a $\log$-log regression of density of fish on total length:

$$
\log \left(n_{F}\right)=\log (0.8798 F)-2.33 \log (\ell) .
$$

To estimate the one remaining parameter, we used the same data from 23 studies that Grant and Kramer used in 
their estimate of $\gamma$ and $\omega$ (see Table 1, Grant and Kramer 1990). However, because we were only interested in the relationship during the first part of the first growing season for a given cohort (the time during which year-class strength is set in many cases, Elliott 1989), we limited the data to those cohorts made up of fish less than $8 \mathrm{~cm}$ (resulting in 18 observations). We found

$$
n_{F}=506 \ell^{-2.33} \text {. }
$$

Equation 2, for a space-limited system with both $\omega$ and $\gamma$ as estimated from regression on these same data, is

[2] $n_{S}=477 \ell^{-2.30}$.

Grant (1993) reevaluated the relationship and concluded that a model II regression would have been more appropriate (Sokal and Rohlf 1981). We re-estimated the parameters using a model II regression on the same data set to find

$$
n=587 \ell^{-2.57} \text {. }
$$

The slope in our food-limitation model, estimated independently of the territory size data, does not differ significantly from the slope of the least squares regression through these data (T-test, $p=0.93$ ) nor the model II regression through these data (T-test using standard error from model I regression (Sokal and Rohlf), $p=0.57$ ). The food limitation model, based on independent, a priori estimates of both slope and the form of the function and only using the data to estimate the intercept, or location of the function, fit the data almost identically to the function that was the best-fit line through those data. The two models are nearly equivalent in their predictions of maximum density as a function of body size in stream salmonids in their first growing season.

Grant and Kramer (1990) compared their model with independent data from the literature. Their model performed remarkably well in describing the effective density limit above which a cohort will exhibit density-dependent mortality, emigration, or growth. Our model suggests a bioenergetic basis for Grant and Kramer's (1990) empirical result.

\section{Density-dependent survival rate}

Above, we derived an expression of effective density of a cohort as a function of sizes of individuals in the cohort and used data compiled by Grant and Kramer (1990) to estimate the parameters of the function. We next suggest a way to use these relationships to describe density-dependent survival in young-of-the-year stream salmonids. Note that when we use the term "survival" here, we are really speaking about "local survival," that is, the proportion of fish that both survive and do not emigrate. Both mortality and emigration are possible responses to density in young stream salmonids (Elliott 1987; Titus 1990). To develop a relationship between survival rates of individual stream salmonids and effective density requires data that include sizes of fish in a cohort and numbers of fish at two sample times. At any sample time $t$, the effective density, $D(t)$, of a cohort ( $\mathrm{g}$ dry wt. $\mathrm{m}^{-2} \cdot \mathrm{d}^{-1}$ ), is the sum of the number of fish in each size class times their size-dependent potential consumption

$$
D(t)=\sum_{i} n_{i}(t) \alpha m_{i}^{\beta}
$$

where $m_{i}$ is the mass ( $\mathrm{g}$ ) of fish in size class $i$ and $n_{i}(t)$ is the number of fish in that size class at time $t$.

Per capita survival rate, $r(t)$, of fish in this cohort at time $t$, should increase with decreasing effective density. Clearly, survival rate cannot increase beyond one, but we believe the maximum will be below one. With decreasing effective density, the population may become limited by something other than food availability. Here, we have assumed that at low effective densities, per capita survival becomes density independent, taking a value $c_{0}$, an estimate of density-independent survival. At high effective densities, per capita survival rate will approach zero:

$$
r(t)=c_{0} D(t)^{-c_{1}} \text {. }
$$

\section{Discussion}

Our goal in deriving a relationship between size of fish and density of fish for age-0 stream salmonids was to be able to represent the interplay between size and density in their effect on survival rates. In modeling the early life history of stream salmonids, we are faced with the dilemma of knowing that local survival rates are density dependent (LeCren 1965; Chapman 1966; Allen 1969; Elliott 1987, 1989, 1990; Titus 1990), but of not having an explicit way to represent this dynamically in a model. It is obvious that we should not model density-dependent survival as a constant number of fish over time when fish are changing sizes over time. Others have proposed that density dependence may be expressed dynamically (i.e., over time as fish are growing) as a constant biomass of fish being supported in a given area, but there is really no mechanistic basis for this assumption and Grant (1993) has recently provided evidence against it. In choosing to model survival in this early life stage as a function of bioenergetic demand on the food resources, we have a logical basis for our assumptions (e.g., Egglishaw 1967; Symons 1971; Dill et al. 1981; Wilzbach 1985) and we can easily include it as a relationship that is dynamic as fish change sizes. Thus, we have derived a representation of density-dependent survival that is $(i)$ flexible over size changes of fish early in their first growing season, (ii) mechanistically based on a justifiable assumption (bioenergetic demand), and (iii) agrees with empirical measures of size and density relationships (comparison with data from Grant and Kramer 1990). This is an important step in our ability to model population dynamics of stream salmonids (Marschall 1991).

Other investigators have also proposed models relating numbers of animals in a given area to body size. Our foodlimitation model is similar to Begon's $-4 / 3$ thinning rule for animal populations, which he based on metabolic rate scaling by a 0.75 exponent of mass (Begon et al. 1986; Elliott 1993). Although Peters (1983) calculated different relationships for different types of animals, he collected estimates of the exponent of the metabolic rate versus body size relationship for fishes in general $(0.78$ and 0.81 , Winberg 1960), teleosts (0.70, Kayser and Heusner 1964; 0.81 and 0.77 , Zotin and Konoplev 1978), salmonids $(0.76 \pm$ 0.032 , Winberg 1960), and salmon (0.775, Brett 1965). 
These values are similar to the exponent used in the model presented here (0.77, Elliott 1975), and thus would yield similar predictions.

Grant and Kramer's (1990) space-limitation model is based on the assumption that individual salmonids require a minimum amount of space (as a function of body size) in a stream, and that there is a constant amount of usable area per area of stream. Our food-limitation model is based on the assumption that an individual salmonid has a minimum requirement of food that scales by a 0.77 exponent of its body mass and that there is a constant amount of food available per area of stream. In general applications of these models, the assumption of constant usable area or constant food available can be interpreted as some expectation of the amount of usable area or food per area of stream, rather than as a strictly invariable resource density.

As well as being useful in modeling early life history of stream salmonids, derivation of this relationship has proven useful in designing experiments involving fish of different sizes. For example, in an experiment to look at growth and survival effects of $\mathrm{pH}$ level on two sizes of brook trout in constructed stream channels with a natural food source, we wanted to equalize the effect that food abundance would have on survival in each of the two sizes of fish (Marschall 1991). This would be necessary to accurately describe a null hypothesis in any experiment investigating size dependence of survival responses. To do this, we equalized the effective density, or the consumption-potential density, between the two size classes in the experiments. In this way, we could attribute size-dependent differences in growth and survival to size-dependent differences in response to the treatment rather than to differential limitation by the food resources.

It is well established that local survival of age- 0 stream salmonids is density dependent. It is also well established that body size plays an important role in many aspects of salmonid life histories (e.g., probability of survival, fecundity, ability to hold feeding territories). To expect to wholly understand the dynamics of stream salmonid populations, we must be able to understand the interplay of size and numbers, of how available resources might support different numbers of different sized individuals, and how different sized individuals will differentially impact the resources available to other individuals. This will require eventual focus on each of many different life stages and processes. As a first step in this direction, our model suggests a way to mechanistically link density-dependent survival in age-0 fish to food availability; "effective density" integrates the effects of body size and number in characterizing the bioenergetic demand of a young cohort on their prey resources.

\section{Acknowledgements}

We thank Andy Dolloff for critical discussions of models and experiments on juvenile stream salmonids. This research was supported by the following agencies: Electric Power Research Institute (EPRI)/Sport Fishing Institute Fellowship in Population Biology (no. 89-02); U.S. Forest Service, Southeastern Station Challenge Cost-Share Agreement (no. 29-547); EPRI COMPMECH Key Species Project on
Salmonids (EPRI under contract RP2932-2 (DOE no. ERD87-672) with the U.S. Department of Energy, under contract no. DE-AC05-840R21400 with Martin Marietta Systems Inc.); grant no. NA16RG0492-01 from the Coastal Ocean Program of NOAA and the UNC Sea Grant College Program Project R/SAB-4; the North Carolina Agricultural Research Station; and the Department of Zoology, The Ohio State University. The views of the authors do not necessarily reflect those of these agencies.

\section{References}

Allen, K.R. 1969. Limitations on production in salmonid populations in streams. In Symposium on Salmon and Trout in Stream. Edited by Institute of Fisheries, University of British Columbia, Vancouver, B.C. pp. 3-18.

Begon, M., Firbank, L., and Wall, R. 1986. Is there a self-thinning rule for animal populations? Oikos, 46: $122-124$.

Brett, J.R. 1965. The relation of size to rate of oxygen consumption and sustained swimming speed of sockeye salmon (Oncorhynchus nerka). J. Fish. Res. Board Can. 22: 1491-1501.

Carlander, K.D. 1969. Handbook of freshwater fishery biology. Vol. 1. Iowa State University Press, Ames, Iowa.

Chapman, D.W. 1966. Food and space as regulators of salmonid populations in streams. Am. Nat. 100: 345-357.

Dill, L.M., Ydenberg, R.C., and Fraser, A.H.G. 1981. Food abundance and territory size in juvenile coho salmon (Oncorhynchus kisutch). Can. J. Zool. 59: 1801-1809.

Egglishaw, H.J. 1967. The food, growth and population structure of salmon and trout in two streams in the Scottish Highlands. Freshwater Salm. Fish. Res. 38: $1-32$.

Elliott, J.M. 1975. Number of meals in a day, maximum weight of food consumed in a day, and maximum rate of feeding for brown trout, Salmo trutta L. Freshwater Biol. 5: 287-303.

Elliott, J.M. 1987. Population regulation in contrasting population of trout Salmo trutta in two Lake District streams. J. Anim. Ecol. 56: 83-98.

Elliott, J.M. 1989. Mechanisms responsible for population regulation in young migratory trout, Salmo trutta. I. The critical time for survival. J. Anim. Ecol. 58: $987-1001$.

Elliott, J.M. 1990. Mechanisms responsible for population regulation in young migratory trout, Salmo trutta. III. The role of territorial behaviour. J. Anim. Ecol. 59: 803-818.

Elliott, J.M. 1993. The self-thinning rule applied to juvenile sea-trout, Salmo trutta. J. Anim. Ecol. 62: 371-379.

Grant, J.W.A. 1993. Self-thinning in stream-dwelling salmonids. Can. Spec. Publ. Fish. Aquat. Sci. 118: 99-102.

Grant, J.W.A., and Kramer. D.L. 1990. Territory size as a predator of the upper limit to population density of juvenile salmonids in streams. Can. J. Fish. Aquat. Sci. 47: 1724-1737. 
Kayser, C., and Heusner, A. 1964. Étude comparative du métabolisme énergétique dans la série animale. J. Physiol. (Paris), 56: 489-524.

Latta, W.C. 1969. Some factors affecting survival of young of the year brook trout, Salvelinus fontinalis (Mitchill), in streams. In Symposium on Salmon and Trout in Streams. Edited by T.G. Northcote. University of British Columbia, Vancouver, B.C. pp. 229-240.

LeCren, E.D. 1965. Some factors regulating the size of populations of freshwater fish. Mitt. Int. Ver. Theor. Angew. Limnol. 13: 88-105.

LeCren, E.D. 1972. The population of young trout (Salmo trutta) in relation to density and territorial behaviour. Rapp. P.V. Réun. Int. Explor. Mer, 164: 241-246.

Marschall, E.A. 1991. Brook trout response to a changing environment: population consequences of growth and survival effects. Ph.D. thesis, North Carolina State University, Raleigh, N.C. U.S.A.

Mason, J.C. 1976. Response of underyearling coho salmon to supplemental feeding in a natural stream. J. Wildl. Manage. 40: 775-788.

Mason, J.C., and Chapman, D.W. 1965. Significance of early emergence, environmental rearing capacity, and behavioral ecology of juvenile coho salmon in stream channels. Can. J. Fish. Aquat. Sci. 22: 173-190.

Noakes, D.L.G. 1980. Social behavior in young charrs. In Chars, Salmonid Fishes of the Genus Salvelinus. Perspectives in vertebrate science. Vol. 1. Edited by E.K. Balon. Dr. W. Junk by Publishers, The Hague, pp. 683-701.
Peters, R.H. 1983. The ecological implication of body size. Cambridge University Press, Cambridge, England.

Sokal, R.R., and Rohlf, F.J. 1981. Biometry. 2nd ed. W.H. Freeman, San Francisco, Calif., U.S.A.

Slaney, P.A., and Northcote, T.G. 1974. Effects of prey abundance on density and territorial behaviour of young rainbow trout (Salmo gairdneri) in laboratory stream channels. Can. J. Fish. Aquat. Sci. 31: 1201-1209.

Symons, P.E.K. 1971. Behavioral adjustment of population density to available food by juvenile Atlantic salmon. J. Anim. Ecol. 40: 569-587.

Titus, R.G. 1990. Territorial behavior and its role in population regulation of young brown trout (Salmo trutta): new perspectives. Ann. Zool. Fenn. 27: $119-130$.

Wilzbach, M.A. 1985. Relative roles of food abundance and cover in determining the habitat distribution of stream-dwelling cutthroat trout (Salmo clarki). Can. J. Fish. Aquat. Sci. 42: 1668-1672.

Winberg, G.G. 1960. Rate of metabolism and food requirement of fishes. Fisheries Research Board Translation Services, No. 194.

Wooton, R.J. 1990. Ecology of teleost fishes. Chapman and Hall, New York.

Zotin, A.I., and Konoplev. V.A. 1978. Direction of the evolutionary progress of organisms. In Thermodynamics of biological processes. Edited by I. Lamprecht and A.I. Zotin. De Gruyter, Berlin, pp. 341-347. 